\title{
Comparative Electrophoretic Profiles of Esterases, and of Glutamate, Lactate and Malate Dehydrogenases, from Aeromonas hydrophila, A. caviae and $A$. sobria
}

\author{
By B. PICARD AND PH. GOULlET* \\ Laboratoire de Microbiologie, Faculté de Médecine Xavier-Bichat (Université Paris VII), \\ 16 rue Henri Huchard, 75018 Paris, France
}

(Received 27 February 1985; revised 2 August 1985)

\begin{abstract}
Esterases, and glutamate, lactate and malate dehydrogenases of 64 Aeromonas hydrophila, $\boldsymbol{A}$. caviae and $A$. sobria strains, were analysed by polyacrylamide agarose gel electrophoresis and by thin layer isoelectrofocusing. On the basis of the isoelectric points of malate dehydrogenase from the three species and the mobility of lactate dehydrogenase from $A$. sobria, 8 species specific zymotypes were defined: three for $\boldsymbol{A}$. hydrophila strains, three for $\boldsymbol{A}$. caviae strains and two for $\boldsymbol{A}$. sobria strains. These zymotypes correlated with previously established DNA hybridization groups. The other electrophoretic data were found to be less useful for distinction between $A$. hydrophila and $A$. sobria strains, but supported differentiation into zymotypes for $A$. caviae strains. The two-dimensional electrophoretic profile established by plotting isoelectric point against electrophoretic mobility of the major esterase illustrated the degree of enzyme polymorphism among the strains of the three species. Variation in electrophoretic patterns within $A$. hydrophila and $A$. caviae might provide useful epidemiological markers.
\end{abstract}

\section{INTRODUCTION}

Motile Aeromonas strains are widely distributed in nature, especially in water (Hazen et al., 1978), including drinking water (Le Chevallier et al., 1982). These bacteria have been implicated in various diseases in a wide range of poikilothermic animals. In man, they cause infections of wounds exposed to contaminated water, and severe septicaemia resulting from intestinal contamination in immunocompromised patients (Wolff et al., 1980; Picard et al., 1984).

Aeromonas hydrophila, A. caviae and A. sobria were clearly separated on the basis of both numerical analysis of characters (Popoff \& Veron, 1976) and DNA hybridization (Popoff et al., 1981). Each of these species contained several hybridization groups: three for $A$. hydrophila, three for $A$. caviae and two for $A$. sobria. These groups were biochemically indistinguishable from one another within each species.

The aim of this work was to evaluate isoelectrofocusing and polyacrylamide agarose gel electrophoresis of esterases, and of glutamate, lactate and malate dehydrogenases, for the interspecies and intraspecies differentiation of motile aeromonads.

\section{METHODS}

Strains and cultivation. The 64 test strains, including reference strains hybridized by Popoff et al. (1981) and fresh strains isolated at Beaujon hospital, are listed in Table 1. Bacteria were inoculated in Fernbach flasks containing $500 \mathrm{ml} \mathrm{L}$ broth (Lennox, 1955) without glucose. Flasks were vigorously shaken for $18 \mathrm{~h}$ at $30^{\circ} \mathrm{C}$ in a reciprocating water bath shaker at about 70 oscillations $\mathrm{min}^{-1}$. Each strain was cultivated at least twice.

Abbreviations: CE, conventional electrophoresis; DFP, di-isopropyl fluorophosphate; GDH, glutamate dehydrogenase; IEF isoelectrofocusing; $\mathrm{LDH}$, lactate dehydrogenase; $\mathrm{MDH}$, malate dehydrogenase; $M_{F}$, electrophoretic mobility; pI, isoelectric point. 
Table 1. Strains examined

\begin{tabular}{|c|c|c|c|c|}
\hline Organism & Code & Strain* & Code & Strain* \\
\hline \multirow[t]{19}{*}{ A. hydrophila } & 1 & HB 92 & 20 & HB 176 \\
\hline & 2 & PV $218^{b}$ & 21 & HB 186 \\
\hline & 3 & HB 27 & 22 & HB 18 \\
\hline & 4 & PV $214^{b}$ & 23 & HB 56 \\
\hline & 5 & PV $216^{b}$ & 24 & HB 164 \\
\hline & 6 & PV $219^{b}$ & 25 & PV $213^{d}$ \\
\hline & 7 & HB 2340 & 26 & PV $212^{d}$ \\
\hline & 8 & HB 29 & 27 & HB 2374 \\
\hline & 9 & HB 93 & 28 & HB 22 \\
\hline & 10 & HB 91 & 29 & HB 2376 \\
\hline & 11 & HB 42 & 30 & PV $543^{d}$ \\
\hline & 12 & PV $314^{c}$ & 31 & HB 165 \\
\hline & 13 & HB 99 & 32 & HB 2393 \\
\hline & 14 & PV $235^{\circ}$ & 33 & HB 2344 \\
\hline & 15 & PV $316^{c}$ & 34 & HB 16 \\
\hline & 16 & PV $201^{\circ}$ & 35 & HB 2 \\
\hline & 17 & HB 59 & 36 & HB 2392 \\
\hline & 18 & HB 63 & 37 & HB 55 \\
\hline & 19 & HB 182 & 38 & HB 2380 \\
\hline \multirow[t]{9}{*}{ A. caviae } & 39 & PV $239^{e}$ & 48 & PV $238^{e}$ \\
\hline & 40 & HB 72 & 49 & HB 101 \\
\hline & 41 & HB 175 & 50 & HB 102 \\
\hline & 42 & HB 88 & 51 & PV $544^{\prime}$ \\
\hline & 43 & HB 67 & 52 & PV $268^{f}$ \\
\hline & 44 & HB 2395 & 53 & PV $247^{f}$ \\
\hline & 45 & HB 77 & 54 & PV $545^{f}$ \\
\hline & 46 & PV $230^{\circ}$ & 55 & HB 96 \\
\hline & 47 & PV $222^{e}$ & 56 & PV $546^{g}$ \\
\hline \multirow[t]{4}{*}{ A. sobria } & 57 & PV $208^{h}$ & 61 & PV $243^{i}$ \\
\hline & 58 & PV $228^{h}$ & 62 & PV $236^{i}$ \\
\hline & 59 & PV $215^{h}$ & 63 & PV $224^{i}$ \\
\hline & 60 & PV $217^{h}$ & 64 & PV $20^{i}$ \\
\hline
\end{tabular}

* PV, reference strains examined by Popoff \& Veron (1976), and subsequently hybridized by Popoff et al. (1981); HB, fresh strains isolated at Beaujon hospital, Clichy, France; $b-i$, hybridization groups 218, 316, 212, 239, $545,546,208$ and 224 respectively. Others not determined.

Electrophoretic analysis. Preparation of extracts, inhibition by di-isopropyl fluorophosphate (DFP), heat inactivation, conventional electrophoresis (CE), isoelectrofocusing (IEF), estimation of electrophoretic mobility ( $M_{F}$ value), establishment of correspondence of bands characterized in the two electrophoretic techniques and esterase staining were all as described previously (Goullet, 1980; Goullet \& Picard, 1984). The $M_{F}$ values were used only comparatively. Glutamate dehydrogenase (GDH) was stained according to the method of Baptist et al. (1969) and lactate dehydrogenase (LDH) and malate dehydrogenase (MDH) according to the method of Siciliano \& Shaw (1976).

\section{RESULTS}

\section{Characterization of enzyme bands}

Isoelectrofocusing. Good resolution with distinct banding was obtained only for $\mathrm{MDH}$ and one esterase (Figs 1 to 3 ); the isoelectric point (pI) could not be determined for GDH because of poorly defined banding. The other enzymes were not detected. With a narrow $\mathrm{pH}$ gradient from pH 5 to $\mathrm{pH} \mathrm{8,} \mathrm{MDH} \mathrm{gave} \mathrm{a} \mathrm{sharp} \mathrm{and} \mathrm{well-stained} \mathrm{main} \mathrm{band,} \mathrm{used} \mathrm{for} \mathrm{pI}$ determination, and 1 to 3 anodic minor bands. With a narrow $\mathrm{pH}$ gradient from $\mathrm{pH} 2.5$ to $\mathrm{pH} 5$, and $\alpha$-naphthyl acetate as substrate, an intensely coloured esterase band (used for pI determination) accompanied by an anodic satellite band was observed.

Polyacrylamide agarose gel electrophoresis. This method was more sensitive than IEF for detecting the enzymes; satisfactory banding patterns were obtained for all enzymes analysed 


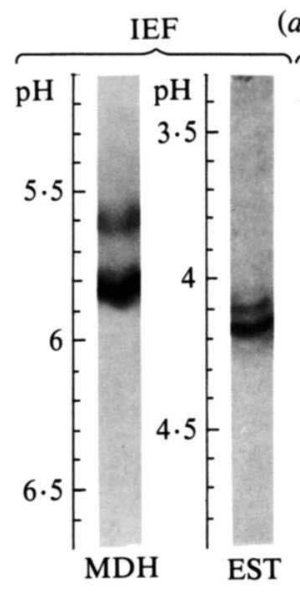

(a)
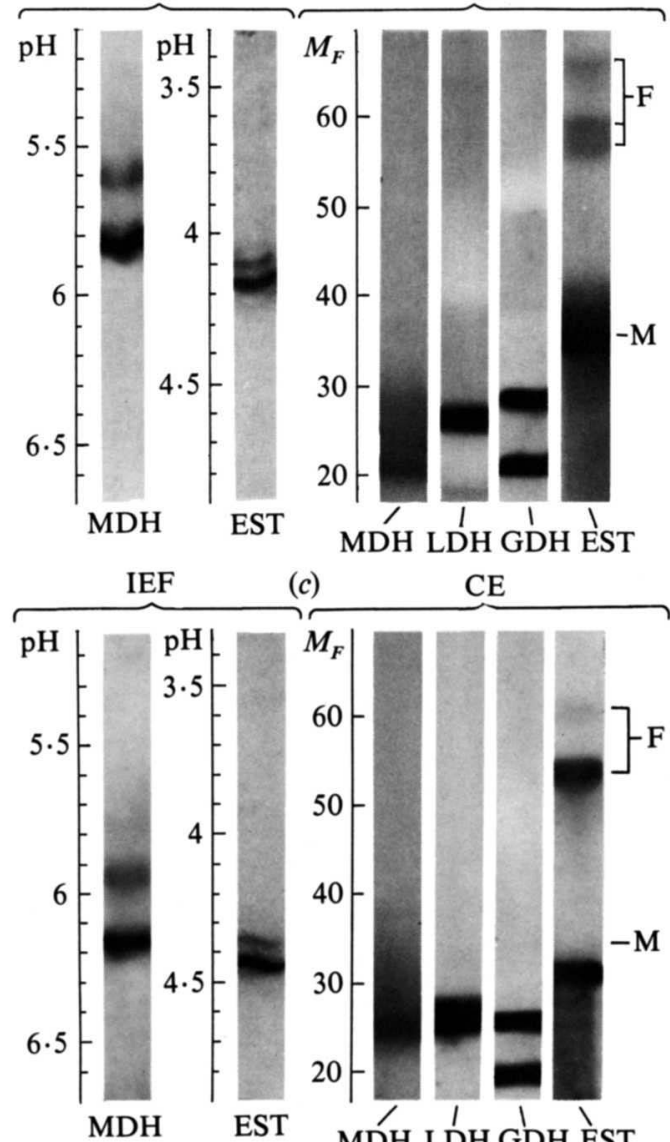

(c)

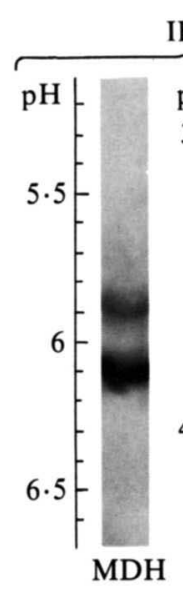

IEF

(b)

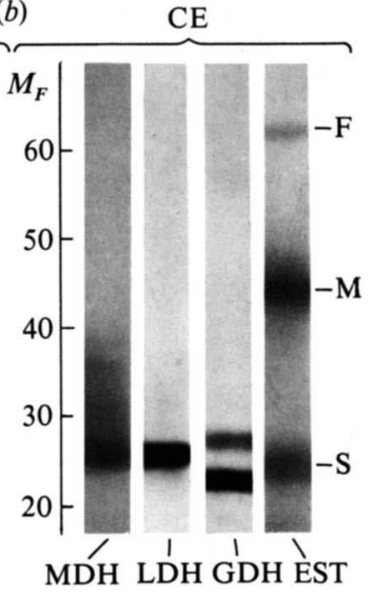

Fig. 1. Zymograms of A. hydrophila. (a) Strain 5 (hybridization group 218) from zymotype $\mathrm{H}_{1} ;(b)$ strain 12 (hybridization group 316) from zymotype $\mathrm{H}_{2} ;(c)$ strain 30 (hybridization group 212) (ATCC 7946) from zymotype $\mathrm{H}_{3}$. For IEF of $\mathrm{MDH}$, the main enzyme band focused as a sharp band which broadened rapidly during the staining.

(Figs 1 to 3). The MDH bands varied in thickness among the strains, the better-defined cathodic limit was chosen for determination of relative mobility. LDH gave 1 to 3 bands, the most intensely stained one being used for mobility determination. GDH gave a single band or two distinctly separated bands. Three kinds of esterases, designated as major (M), fast (F) and slow (S), were differentiated by hydrolytic activity and by sensitivity to heat and to DFP. The band $M$, which was identified as the esterase obtained by IEF, consisted of a sharp and intensely stained band which hydrolysed $\alpha$ - and $\beta$-naphthyl acetates and butyrates. This esterase remained active after $10 \mathrm{~min}$ treatment at $60^{\circ} \mathrm{C}$ and was resistant to $10^{-3} \mathrm{M}$-DFP. Esterase $\mathrm{F}$ was resolved into 1 to 4 bands; the mobility of the anodic band was chosen for relative mobility determination. This esterase hydrolysed $\alpha$ - and $\beta$-naphthyl acetates and was inactivated by $10^{-3} \mathrm{M}$-DFP and by heat treatment. Esterase $\mathrm{S}$, which was similar in hydrolysing activities and sensitivity to DFP and to heat to esterase $\mathrm{F}$, always migrated more slowly than esterase $\mathrm{M}$. LDH, GDH, MDH, esterase M and esterase F (except for strain 56) were detected in all strains.

\section{Ranges of $\mathrm{pI}$ and mobilities of enzyme bands among the strains}

Electrophoretic relationships between the strains were established by numerous replicate runs comparing enzyme bands side by side on the same gel. The reproducibility of the results was confirmed in several ways. For $\mathrm{pI}$ values, all the samples coalesced as a single line after IEF when they were loaded at different positions on the gel, and samples remained in the same line with no additional bands being observed when IEF was continued for an additional $30 \mathrm{~min}$ period to condense the focused region. All values of both $\mathrm{pI}$ and $M_{F}$ were tested by comparing 

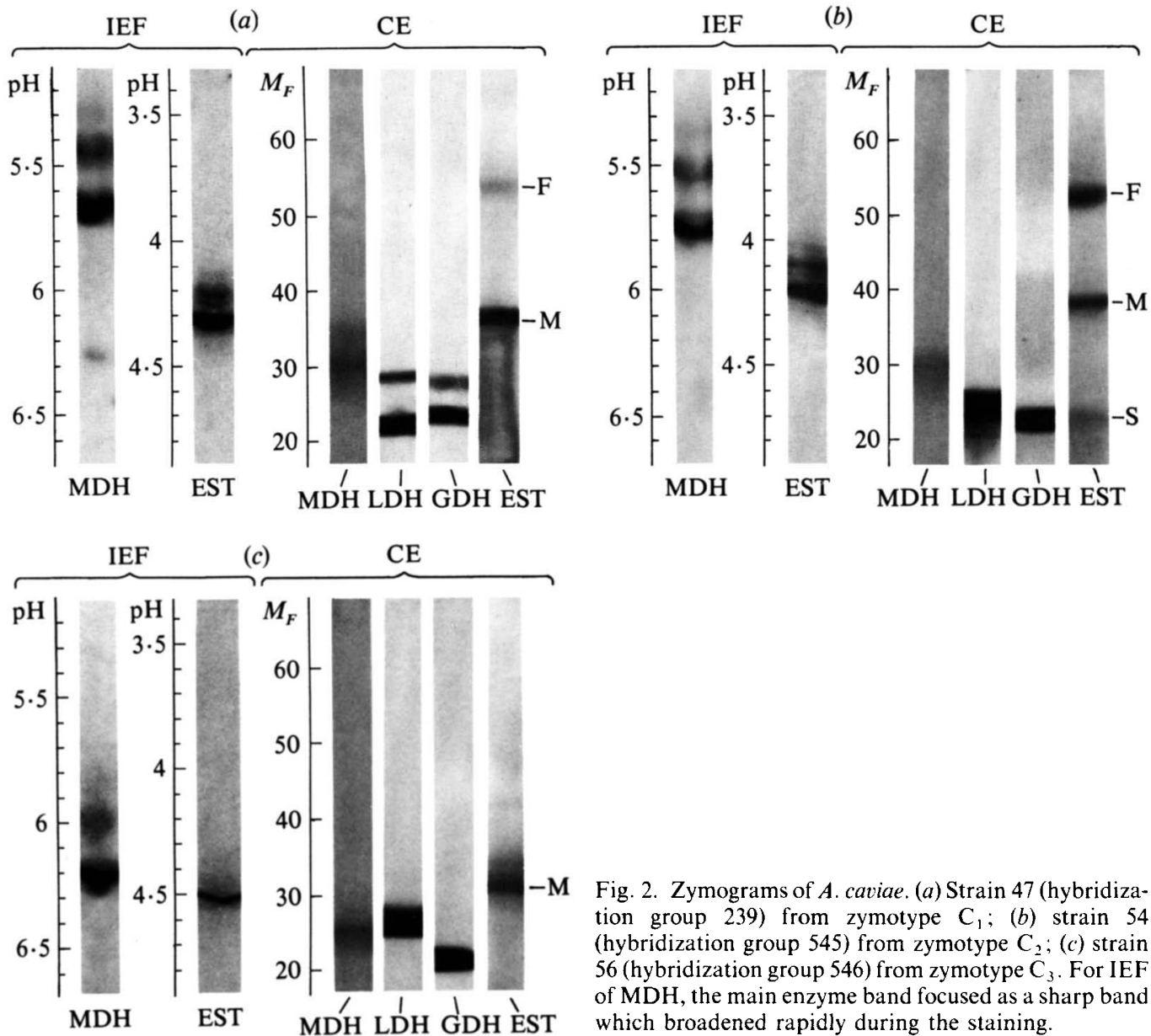

(c) $\quad \mathrm{CE}$

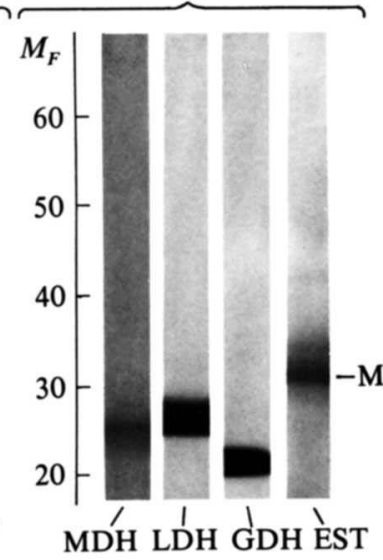

Fig. 2. Zymograms of A. caviae. (a) Strain 47 (hybridization group 239) from zymotype $\mathrm{C}_{1} ;(b)$ strain 54 (hybridization group 545) from zymotype $\mathrm{C}_{2} ;(c)$ strain 56 (hybridization group 546) from zymotype $\mathrm{C}_{3}$. For IEF of $\mathrm{MDH}$, the main enzyme band focused as a sharp band which broadened rapidly during the staining.

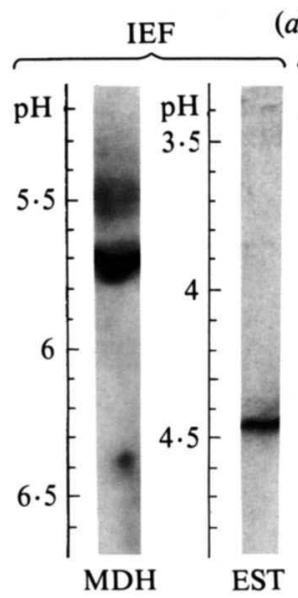

(a)

CE

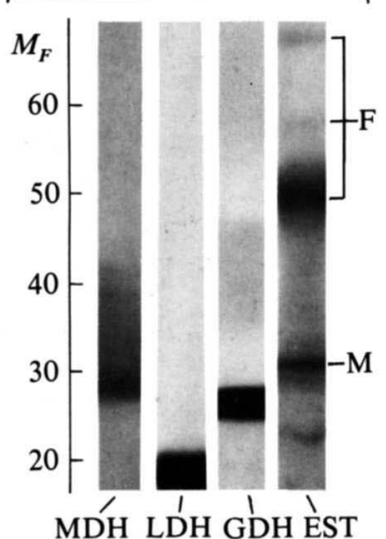

IEF

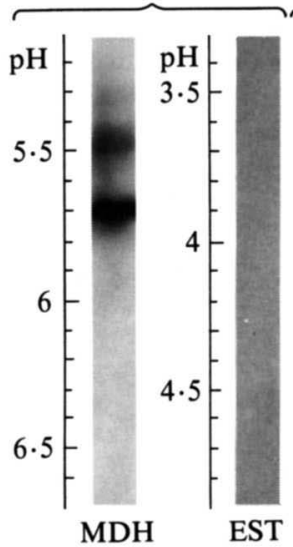

CE

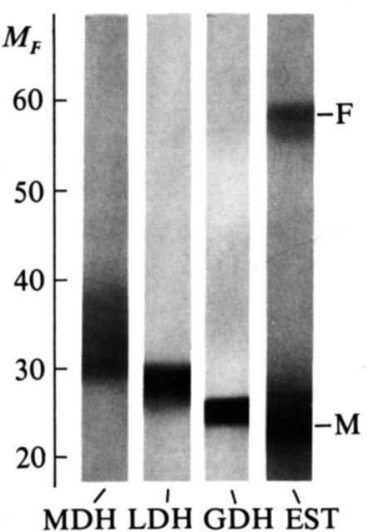

Fig. 3. Zymograms of $A$. sobria. (a) Strain 58 (hybridization group 208) from zymotype $\mathrm{S}_{1} ;($ b) strain 63 (hybridization group 224) from zymotype $\mathrm{S}_{2}$. For IEF of $\mathrm{MDH}$, the main enzyme band focused as a sharp band which broadened rapidly during the staining. 
Table 2. Ranges of isoelectric points $(p I)$ and mobilities $\left(M_{F}\right)$ of enzyme bands in strains of A. hydrophila, A. caviae and A. sobria

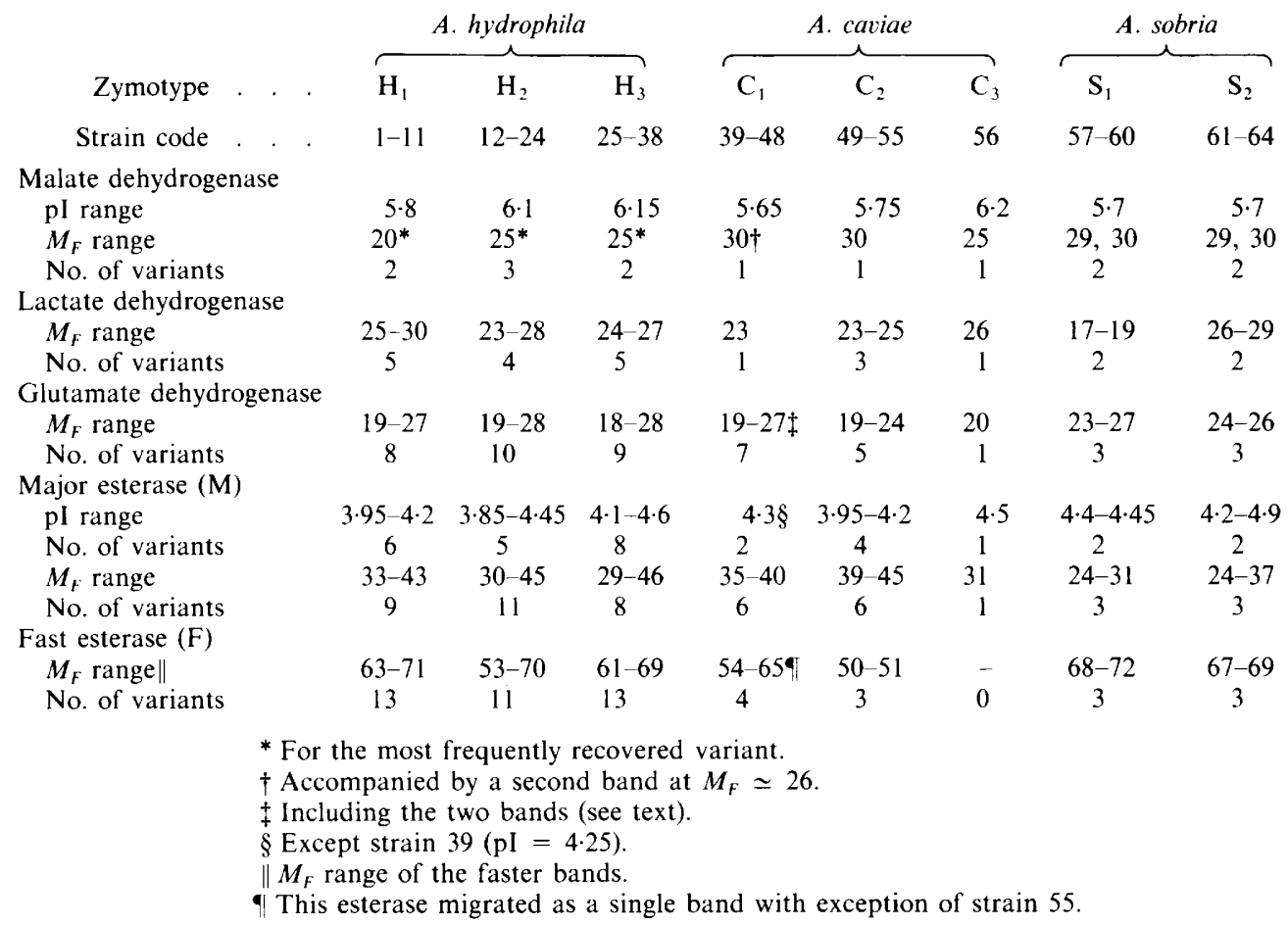

each new strain with reference strains in all electrophoretic runs; 4 to 12 extracts of the same strain were tested and had the same $\mathrm{pI}$ in IEF and the same electrophoretic relationship in CE. Table 2 shows the pI and $M_{F}$ values of enzymes detected in the strains.

Malate dehydrogenase. On the basis of the pI values of this enzyme, which ranged from 5.65 to 6.2, seven zymotypes were defined. (i) A. hydrophila strains (Fig. 1): zymotype $\mathrm{H}_{1}$ (11 strains including four reference strains of hybridization group 218) with a $\mathrm{pI}$ of $5 \cdot 8$; zymotype $\mathrm{H}_{2}(13$ strains including four reference strains of hybridization group 316) with a pI of $6 \cdot 1$; zymotype $\mathrm{H}_{3}$ (14 strains including three reference strains of hybridization group 212) with a pI of 6.15. (ii) $A$. caviae strains (Fig. 2): zymotype $\mathrm{C}_{1}$ (10 strains including four reference strains of hybridization group 239) with a pI of 5.65 ; zymotype $\mathrm{C}_{2}$ (seven strains including four reference strains of hybridization group 545) with a pI of $5 \cdot 75$; zymotype $C_{3}$ (strain 546 with a pI of $6 \cdot 2$ ). (iii) $A$. sobria strains (Fig. 3): zymotype S with a pI of 5.7. MDH had identical mobilities within each zymotype of $A$. hydrophila and $A$. caviae defined by IEF, except for strains 1 and 11 (zymotype $\mathrm{H}_{1}$ ), strains 3 and 16 (zymotype $\mathrm{H}_{2}$ ) and strain 37 (zymotype $\mathrm{H}_{3}$ ); in addition, strains of zymotype $\mathrm{C}_{1}$ gave two distinct bands. In $A$. sobria strains, MDH had two mobilities.

Lactate dehydrogenase. Strains of $A$. hydrophila and $A$. caviae had LDH which had identical mobility in strains of zymotype $\mathrm{C}_{1}$ but variations among the strains of zymotypes $\mathrm{C}_{2}$ and $\mathrm{H}_{1}, \mathrm{H}_{2}$ and $\mathrm{H}_{3}$. Strain 546 (zymotype $\mathrm{C}_{3}$ ) was distinguished from other $A$. caviae strains by faster mobility of LDH. In $A$. sobria strains, LDH had two clusters of mobility (Fig. 3) which defined two zymotypes: zymotype $S_{1}\left(M_{F} \simeq 17\right.$ and $\left.M_{F} \simeq 19\right)$ for the four reference strains of hybridization group 208 , and zymotype $\mathrm{S}_{2}\left(M_{F} \simeq 26\right.$ and $\left.M_{F} \simeq 29\right)$ for the four reference strains of hybridization group 224 .

Glutamate dehydrogenase. In strains of $A$. hydrophila and $A$. sobria, GDH had a high electrophoretic polymorphism. In $A$. caviae, GDH had a single band in strains of zymotypes $\mathrm{C}_{2}$ and $\mathrm{C}_{3}$ and, in strains of zymotype $\mathrm{C}_{1}$, one anodic band $\left(M_{F} \simeq 27\right)$ (except for two strains) was accompanied by another electrophoretically variable band. 


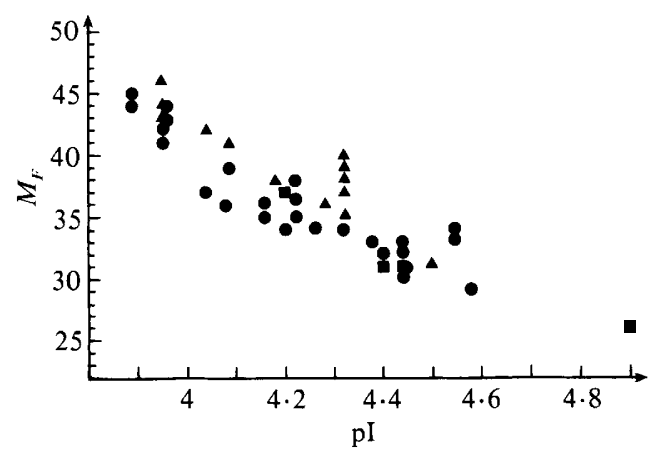

Fig. 4. Two-dimensional electrophoretic profile of esterase $\mathrm{M}$ from $A$. hydrophila, $A$. caviae and $A$. sobria strains. Each allozyme is defined by $\mathrm{pI}$ and $M_{F} . \boldsymbol{O}, A$. hydrophila $; \boldsymbol{\Delta}, A$. caviae; $\mathbf{\square}, \boldsymbol{A}$. sobria.

Esterases. The pI value of esterase $\mathrm{M}$ varied from 3.85 to 4.9 (Figs 1 to 3). The strains of each zymotype defined by the $\mathrm{pI}$ of MDH had esterases which had 4 to 8 distinct pI values, with the exception of strains of zymotype $\mathrm{C}_{1}$, the esterases of which had only two distinct pI values. The last one of these ( $\mathrm{pI}=4 \cdot 3$ ) was identical for nine strains of this zymotype. CE revealed high variability of esterases $M$ and $F$. Esterase $S$ was detected in only some strains of the three species. A two-dimensional electrophoretic profile (Goullet \& Picard, 1985), established by plotting pI against electrophoretic mobility for esterase M (Fig. 4), showed that several mobility variants fall into a single $\mathrm{pI}$, and that conversely, several $\mathrm{pI}$ variants occurred for a single mobility. Thus the number of allozymes resolved by this procedure (40) was considerably higher than the number resolved by CE (19) or by IEF (18).

Copies of diagrammatic representations of isoelectric focusing patterns of malate dehydrogenases and of esterases, and electrophoretic patterns of lactate, glutamate and malate dehydrogenases and esterases from all the test strains, have been deposited with the British Library Lending Division, Boston Spa, Yorkshire LS23 7BQ, UK, as Supplementary Publication no. SUP 28021 (11 pp.). (Copies may be obtained from the BLLD on demand; wherever possible, requests should be accompanied by prepaid coupons, held by many university and technical libraries and by the British Council.)

\section{DISCUSSION}

Comparison of data obtained by IEF and CE showed that the latter technique was more sensitive for both detection of enzyme activity and evaluation of electrophoretic variability. The failure to detect enzyme activity ( $\mathrm{LDH}, \mathrm{GDH}$, esterases $\mathrm{F}$ and S) by IEF has already been observed for some esterases produced by Yersinia strains (Goullet \& Picard, 1984), and inactivation of enzymes at acidic or basic $\mathrm{pI}$ values, or interactions between carrier ampholytes and proteins, could offer an explanation.

On the basis of pI values of MDH produced by strains of the three Aeromonas species, and $\boldsymbol{M}_{F}$ values of LDH produced by strains of $A$. sobria, eight species-specific zymotypes were defined. These zymotypes correlated respectively with the eight biochemically indistinguishable groups previously defined on the basis of DNA hybridization (Popoff et al., 1981). The three zymotypes of $A$. hydrophila, and the zymotypes $\mathrm{C}_{1}$ and $\mathrm{C}_{2}$ of $A$. caviae, were observed in fresh isolates as well as in reference hybridized strains. The other electrophoretic data were less useful for distinction between $A$. hydrophila and $A$. sobria strains but supported the individuality of the three zymotypes of $A$. caviae. Strains of zymotype $\mathrm{C}_{1}$ were distinguished from strains of the other Aeromonas zymotypes by two bands of $\mathrm{MDH}\left(M_{F} \simeq 26\right.$ and $\left.M_{F} \simeq 30\right)$, and from strains of zymotype $\mathrm{C}_{2}$ by the electrophoretic homogeneity of LDH, the anodic band of GDH and the higher $\mathrm{pI}$ values of esterase $\mathrm{M}$ (Table 2). Strain 56 (zymotype $\mathrm{C}_{3}$ ) was differentiated from the other $A$. caviae strains by a distinct pI value of esterase M (4.5), by distinct mobilities of LDH, 
MDH and esterase M, and by the absence of esterase F. Consequently this particular enzyme profile is in agreement with the possibility of this strain representing a third hybridization group of $A$. caviae (Popoff et al., 1981). Strains of $A$. hydrophila had the highest variability whereas strains of $A$. caviae were electrophoretically less variable. Strains of zymotype $C_{1}$ were the most homogeneous set encountered in this study. Strains of $A$. sobria appeared to be polymorphic but the number of strains examined was too low to be considered completely representative of the species. The two-dimensional electrophoretic profile of esterase $M$ refined considerably the degree of enzyme polymorphism among the strains of the three species, and showed that for the same pI value, the mobilities of the enzymes from $A$. caviae strains were generally greater than those from $A$. hydrophila strains (Fig. 4).

Methods of typing Aeromonas for epidemiological purposes are required because of the prevalence of these bacteria in the aquatic environment (Hazen et al., 1978), and their capacity to cause infections, particularly in immunocompromised hosts (Wolff et al., 1980; Cookson et $a l ., 1981$ ). The high degree of enzyme polymorphism among the strains of $A$. hydrophila and $A$. caviae might provide epidemiological markers. Thus IEF of MDH and esterase could be proposed as a first screening, which could be subsequently refined by CE of esterases, and eventually of LDH and GDH. Electrophoretic typing of esterases, which has the advantage of detecting three kinds of enzymes using one substrate ( $\alpha$-naphthyl acetate) in the same electrophoretic run, has recently demonstrated the epidemiologic complexity of nosocomial infections caused by $A$. hydrophila and $A$. caviae (Picard \& Goullet, 1984).

The authors thank Dr M. Popoff for hybridized strains and Madame C. Gaillard and Madame N. Petit for technical assistance. This work was supported by a grant from the Conseil Scientifique de la Faculté XavierBichat (Université Paris VII).

\section{REFERENCES}

Baptist, J. N., Shaw, C. R. \& Mandel, M. (1969). Zone electrophoresis of enzymes in bacterial taxonomy. Journal of Bacteriology 99, 180-188.

Cookson, B. D., Houang, E. C. \& LeE, J. V. (1981). Clustering of Aeromonas hydrophila septicaemia. Lancet 2, 1232.

Goullet, PH. (1980). Distinctive electrophoretic patterns of esterases from Klebsiella pneumoniae, $K$. oxytoca, Enterobacter aerogenes and E. gergoviae. Journal of General Microbiology 117, 483-491.

Goullet, Ph. \& PiCARD, B. (1984). Distinctive electrophoretic and isoelectric focusing patterns of esterases from Yersinia enterocolitica and Yersinia pseudotuberculosis. Journal of General Microbiology 130, 1471-1480.

Goullet, Ph. \& Picard, B. (1985). A two-dimensional electrophoretic profile for bacterial esterases. Electrophoresis 6, 132-135.

Hazen, T. C., Fliermans, C. B., Hirsch, R. P. \& EsCH, G. W. (1978). Prevalence and distribution of Aeromonas hydrophila in the United States. Applied and Environmental Microbiology 36, 731-738.

Le Chevallier, M. W., Evans, T. M., Seidler, R. J., Daily, O. P., Merrell, B. R., Rollins, D. M. \& JOSEPH, S. W. (1982). Aeromonas sobria in chlorinated drinking water supplies. Microbial Ecology 8, 325-333.
LenNox, E. S. (1955). Transduction of linked characters of the host by bacteriophage PI. Virology $\mathbf{1}$, 190-206.

Picard, B. \& Goullet, Ph. (1984). Esterase electrophoresis: a new epidemiological screening test for Aeromonas hydrophila hospital infection. Journal of Hospital Infection 5, 335-337.

Picard, B., Arlet, G. \& Goullet, Ph. (1984). Septicémies à Aeromonas hydrophila. Aspects epidémiologiques. Quinze observations. La Presse Medicale 13, 1203-1205.

Popoff, M. \& Veron, M. (1976). A taxonomic study of the Aeromonas hydrophila-Aeromonas punctata group. Journal of General Microbiology 94, 11-22.

Popoff, M., Coynault, C., Kiredjian, M. \& Lemelin, M. (1981). Polynucleotide sequence relatedness among motile Aeromonas species. Current Microbiology 5, 109-114.

Siciliano, M. \& Shaw, C. R. (1976). Separation and visualization of enzymes on gels. In Chromatographic and Electrophoretic Techniques, 4th edn, vol. 2, pp. 185-209. Edited by I. Smith. Chicago: Yearbook Medical Publishers.

WolfF, R. L., Wiseman, S. L. \& Kittchens, C. S. (1980). Aeromonas hydrophila bacteremia in ambulatory immunocompromised hosts. American Journal of Medicine 68, 238-242. 